\title{
Concordance of Congenital Heart Defect in Monozygotic Twins in Brazil
}

Adail Orrith Liborio Neto ${ }^{10}$ and Aline Reis Bereta ${ }^{2}$

Universidade Federal do Rio de Janeiro - Unidade Macaé, ${ }^{1}$ Macaé, RJ - Brazil Hospital Público Municipal Dr. Fernando Pereira da Silva, ${ }^{2}$ Macaé, RJ - Brazil

\section{Abstract}

Tetralogy of Fallot (TOF) consists of four cardiac changes: interventricular communication, pulmonary stenosis, aortic dextroposition and right ventricular hypertrophy. The prevalence is 0.1 per 1,000 live births. A primiparous mother with gestational age of 38 weeks came to the emergency. At the time, it was verified in her twin pregnancy that one fetus had TOF, thus a pregnancy interruption was scheduled for the following day. In the neonatal physical examination of both, localized acrocyanosis, regular heart rhythm with the presence of a heart murmur, and good peripheral perfusion were found. The echocardiogram of twin 1 revealed: patent foramen ovale; a wide perimembranous interventricular communication of misalignment, with the aorta riding the septum by 50\%; hypertrophied and long infundibulum with pulmonary infundibulo-valvular stenosis, with a maximum systolic gradient of $66 \mathrm{~mm}$ $\mathrm{Hg}$; both pulmonary arteries presented dimensions of $0.35 \mathrm{~mm}$; pulmonary valve annulus: $0.56 \mathrm{~mm}$; and patent ductus arteriosus measuring $0.19 \mathrm{~mm}$. The echocardiogram of twin 2 showed: patent foramen ovale; a wide perimembranous interventricular communication of misalignment, with the aorta riding the septum by $50 \%$; hypertrophied infundibulum with stenosis pulmonary infundibulo-valve, with a maximum systolic gradient of $33 \mathrm{~mm} \mathrm{Hg}$; reduced confluent pulmonary arteries; right pulmonary artery measuring $0.40 \mathrm{~mm}$ and left pulmonary artery measuring $0.55 \mathrm{~mm}$; pulmonary valve annulus measuring $0.72 \mathrm{~mm}$; a closed arterial canal, and mild

\section{Keywords}

Heart Defects,Congenital, Twins,Monozygotic; Pregnancy Twin; Tetralogy of Fallot/surgery; Heart Septal Ventricular/surgery; Neonatal. aortic regurgitation. Tetralogy of Fallot is a multifaceted syndrome with a high prevalence in pediatrics. This case is the first case of congenital heart defect concordance for TOF in monozygotic twins in Brazil.

\section{Introduction}

Tetralogy of Fallot (TOF) is a common congenital heart malformation, with an incidence of 0.1/1,000 newborns. ${ }^{1}$ The disease was first described in 1671 by the Danish anatomist Niels Stens on a fetus with ectopia cordis. However, only in 1888, with the French physician Arthur Fallot, is the existence of a single pathological process explaining the disease that he himself called la maladie bleue (Blue disease) proposed. ${ }^{2}$ Based on autopsies of patients with the so-called "blue disease", Arthur Fallot described four morphological abnormalities in the heart: ventricular septal defect, pulmonary stenosis, biventricular origin of the aorta, and right ventricular hypertrophy. ${ }^{1}$

The TOF diagnosis can be performed on a prenatal fetus by ultrasound and later confirmed with fetal echocardiography. In other situations, the diagnosis is only made after birth due to the child's clinical condition, which can vary depending on the degree of obstruction at the level of the right ventricular outflow tract. Although the prenatal diagnosis has several advantages for the child and family, it still does not match most cases. ${ }^{2}$

While there may be variation in specific anatomical variations, the TOF is responsible for between $7 \%$ and $10 \%$ of all congenital heart diseases in the United States, making it one of the most common congenital lesions, requiring early intervention in life. ${ }^{3}$ In Brazil, 973 cases of TOF were registered in 2010, but it is well-known that underreporting is high. ${ }^{4}$ TOF can be part of some genetic syndromes, such as Down's syndrome, Klinefelter's, Di George's, Goldenhar's,

Mailing Address: Adail Orrith Liborio Neto

Cidade Universitária da Universidade Federal do Rio de Janeiro, Macaé. Rua Aloízio da Silva Gomes, 50. Postal Code: 27930-560, Novo Cavaleiros, Macaé, RJ - Brazil. E-mail: adail_orrith@hotmail.com 
Robinow's, Shprintzen's, conotruncal anomaly, and Pentalogy of Cantrell, and may even be associated with teratogens, such as trimethadione, thalidomide, and phenylketonuria. When it occurs alone, it is rarely Family-based. ${ }^{5}$ The incidence of congenital heart defects among children is only 6/1,000 live births, compared to 17.2/1,000 in monozygotic twins, as compared to dizygotic twins, where the incidence is approximately $8 / 1,000 .^{6}$

\section{Case report}

SS, a 24-year-old black woman, of Haitian origin, was admitted to the maternity emergency ward, in labor, at a gestational age of 38 weeks. The mother, primiparous, revealed that the pregnancy had been uneventful, though no prenatal exams had been conducted. The obstetric examination revealed a uterine bottom of $45 \mathrm{~cm}$; a fetal heart rate of $140 \mathrm{bpm}$ and $144 \mathrm{bpm}$; and fetal movements present. Upon obstetric emergency examination, it was found that in the twin pregnancy, one fetus presented TOF, and was thus admitted for maternity and pregnancy termination by Caesarean section, scheduled for the next day.

Twin 1, female, had Apgar scores of 7 and 8 (first and fifth minutes respectively), a weight of 2,640 g, a length of $46 \mathrm{~cm}$, and a cephalic perimeter of $34 \mathrm{~cm}$. Twin 2, also female, presented an Apgar score of 8 and 8, a weight of $3015 \mathrm{~g}$, a length of $47.5 \mathrm{~cm}$, and a cephalic perimeter of $35 \mathrm{~cm}$. In the neonatal physical examination of both, localized cyanosis, of the acrocyanosis type, was verified, coupled with primitive reflexes, universally audible breath sounds and no adventitious noise, a regular heart beat with the presence of a murmur in all cardiac foci, and good peripheral perfusion. No other changes were found in the exam. It was hypothesized that the other twin had the same diagnosis as her sister.

The echocardiogram demonstrated patent foramen ovale, large interventricular communication, moderate arterial canal patency, aorta dextroposition, anterior deviation of the interventricular septum with the presence of a long and hypertrophied infundibulum, and reduced caliber pulmonary arteries, confirming the diagnosis of TOF in both newborns.

The daily physical examinations showed that both were eupneic, for the neonatal age, breathing in ambient air without difficulties, with a regular heart beat, with the presence of a heart murmur $3+/ 6+$ in all cardiac foci, and acrocyanosis on their hands and feet when they cried. The twins did not need ventilatory or hemodynamic support during hospitalization. The conduct was clinical support with routine physical exams and echocardiograms weekly to control the neonatal outcome until they could be referred.

The following week, an echocardiogram was again performed by a pediatric specialist. Twin 1's exam revealed patent foramen ovale; a perimembranous wide interventricular communication of poor alignment, with an aorta dextroposition in 50\%; infundibulum with pulmonary infundibular-valvular stenosis, with a maximum systolic gradient of $66 \mathrm{~mm} \mathrm{Hg}$; as well as confluent and small pulmonary arteries. The right pulmonary artery measured $0.35 \mathrm{~mm}$ and the left pulmonary artery measured $0.35 \mathrm{~mm}$; the pulmonary valve ring measured $0.56 \mathrm{~mm}$ and the patent ductus arteriosus measured $0.19 \mathrm{~mm}$.

Twin 2's echocardiogram showed: patent foramen ovale; a perimembranous wide interventricular communication of poor alignment, with an aorta dextroposition in 50\%; hypertrophied infundibulum, with pulmonary infundibular-valvular stenosis and with a maximum systolic gradient of $33 \mathrm{~mm} \mathrm{Hg}$; confluent pulmonary arteries that were reduced size. The right pulmonary artery measured $0.40 \mathrm{~mm}$ and the left pulmonary artery measured $0.55 \mathrm{~mm}$; the pulmonary valve ring measured $0.72 \mathrm{~mm}$; closed ductus arteriosus and mild aortic insufficiency were also observed.

The twins have evolved with stable frameworks and were discharged on the fifteenth day of hospitalization for a consultation in a cardiopediatric outpatient clinic. They were then forwarded for monitoring in a referral hospital for follow-up and for future surgical approaches. An informed consent was received from the patient's mother.

\section{Discussion}

Congenital heart disease is considered the most common of all congenital defects, corresponding to more than $40 \%$ of all identified defects at birth. Congenital heart diseases with conotruncal defects, which are characterized by changes in the outflow tract of the heart, correspond to about $50 \%$ of all congenital heart diseases found in newborns. This group consists of TOF, the interrupted aortic arch, truncus arteriosus, a ventricular septal defect with pulmonary atresia, transposition of the great arteries, and double-outlet right ventricle. Together with transposition of the 
great arteries, TOF is one of the most common cyanotic entities, and its prevalence is around $11 \%$ of live births with congenital heart disease. ${ }^{1}$

From the clinical anatomical perspective, TOF is due to the anterocephalic deviation of the infundibular septum, the abnormality that produces essential pulmonary stenosis, in such a way that the right ventricular infundibulum adopts a path through a wide and narrow cylinder. A thick, hypertrophic trabecula in the ventricular free wall, which is dependent, in part, on the so-called septum-marginal trabeculae, which contributes to the obstruction. The terminal portion of the septum is diverted anteriorly and to the right. This alteration prevents adequate fusion of the interventricular septum, narrows the exit of the right ventricle to the pulmonary artery, and widens the aortic root, with its cavalcade on the septum. ${ }^{1-2}$

The etiology is multifactorial, lying associated with maternal consumption of retinoic acid, poorly controlled diabetes, and maternal phenylketonuria. Some chromosomal abnormalities also associate themselves with the disease, including trisomy 21 (Down's syndrome), 18 (Edwards' syndrome), and 13 (Patau's syndrome). There is a strong correlation between TOF and 22 chromosome microdeletions in the region $\mathrm{q}^{2}{ }^{2}$ especially in those children with right aortic arch (17\%). ${ }^{1}$ According to clinical tests, neither twin presented a phenotype typical of genetic diseases, but, due to a lack of resources, no specific genetic test was requested.

Congenital heart defects are more common in monozygotic compared to dizygotic twins. The incidence of agreement, that is, twins being affected, is about $5 \%$ for dizygotic twins, as compared to $25 \%$ in monozygotic twins. ${ }^{7}$ There are few reports of multiple births associated with TOF, few cases of specific congenital heart defects of agreement for TOF, and rare cases of phenotypic discordance for TOF. Some reports make the association with 22q11 deletion syndrome, while others do not have this information or no association between them.

In the literature, one of the first reported cases of multiple births associated with TOF was in 1970, where Haar B.G. ${ }^{8}$ in the Netherlands reported a case of monozygotic twin accordance with TOF associated with cleft palate, vesicoureteral reflux and pre-auricular fistulas. In 1974, Adams H.D. ${ }^{9}$ reported one of the first cases of identical twins with TOF diagnosed and successfully corrected in Texas (USA). In 1967, also in Texas, Nora et al., ${ }^{10}$ identified a set of twins with TOF when she conducted an analysis of monozygotic twins. She also proposed an association of $25 \%$ agreement for cardiac involvement in monozygotic twins after combining the results of nine previous studies. In Ohio (USA) in 1991, Cassidy et al., ${ }^{11}$ identified a case of triplet siblings, all three infants presented TOF, each with a different type and degree of pulmonary stenosis.

In China in 2001, Lu et al., ${ }^{12}$ reported monozygotic twins concordant for 22q11.2 microdeletion, but discordant for standardization. Both twins showed identical intracardiac defects, including TOF with pulmonary atresia. In France, also in 2001, Laugel et al., ${ }^{13}$ discussed a case of monozygotic twins affected by TOF, though the prenatal diagnosis excluded microdeletion 22q11. In 2002, Patel et al., ${ }^{14}$ in India, reported seven-yearold monozygotic twins with TOF. This was one of the first case reports of concordance of heart disease among twins detected in older children. In 2010 in Mexico, Alva et al., ${ }^{15}$ reported 8-year-old monozygotic male twins, with almost identical phenotypes. Both had $\mathrm{O}+$ blood, and the fluorescence in situ hybridization tests of both boys were negative for the microdeletion of chromosome 22q11. In 2016, in India, Govind ${ }^{7}$ reported an example of twins born without adverse prenatal factors but with twin-totwin transfusion syndrome. It was observed that both babies had TOF with pulmonary atresia.

In cases of phenotypic discordance of heart defect associated with monozygotic twinning, some cases in the literature stand out. In 1995, Goodship et al., ${ }^{16}$ discussed the case of monozygotic twins concordant for 22q11.2 deletion, but discordant for the clinical phenotype. Both boys show typical dysmorphic features with short palpebral fissures, square nasal tip, small mouth, and nasal speech, but only one twin presented TOF. In 1998, Yamagishi et al., ${ }^{17}$ reported monozygotic male twins with 22q11.2 deletion and discordant phenotypes. The twins presented a transfusion twin-totwin syndrome. One twin, had TOF associated with a characteristic facial appearance, swallowing dysfunction, anal atresia, short stature, and mental retardation, while the second twin had a facial characteristic appearance, but no other sign of 22q11 deletion syndrome. In 2005, Kádár. ${ }^{18}$ reported the first case published in Hungary, to the best of our knowledge, of two twin children with conotruncal anomalies (one having truncus arteriosus communis and the other having TOF), which have been associated with the deletion of chromosome $22 \mathrm{q} 11$. Finally, in 2009, in Cuba, Moreno et al., ${ }^{19}$ reported a case of a baby at the age of 10 months who was born with TOF 
and distal arthrogryposis, although his twin brother was born without congenital defects; however, there was no association with SD 22q11.2.

In the case of the twins of the present case, there is great agreement regarding the cardiac defect; however, one twin has a mild aortic insufficiency different from the sister, the pulmonary infundibulum-valvar of both twins have differences in the stenosis diameters, and the pulmonary arteries are of small but distinct sizes. However, they did not have the SD 22q11.2 phenotype. There are no reports in Brazil of this relation of agreement of TOF in twins.

Furthermore, histological studies of the myocardium of patients with TOF showed the presence of hypertrophy, cardiomyocyte disarray, and various degrees and types of fibrosis, edema, infiltration by mononuclear cells and degenerative changes, such as vacuolar degeneration of cardiomyocytes. It was observed that at birth there is no difference between the diameter of cardiomyocytes of TOF and normal patients. After birth, this diameter increases progressively and gradually, and connective tissue proliferation occurs proportionally to hypertrophy and age. These findings support the hypothesis that in fetal life, ventricular septal defect and low left ventricular afterload relieve the pressure overload imposed by the obstruction of the right ventricular outflow tract, decreasing the stimulus for right ventricular remodeling. ${ }^{20}$

After birth the physiological increase in afterload of the left ventricle, which is reflected in the right ventricle through the ventricular septal defect, adds to that imposed by the obstruction of the right ventricular outflow tract, generating great stimulus to right ventricular remodeling. Thus, we can consider that the right ventricular remodeling possibly occurs mainly in the post-natal period. ${ }^{20}$ Right ventricular hypertrophy is a secondary response to increased afterload. There are a few additional changes that occur with some frequency in this disease: obstruction at the level of branches of the pulmonary artery, coronary anomalies, right aortic arch, and additional defects in the interventricular septum. Thus, blood ejected by the ventricle has two possible routes: the outflow tract anatomically assigned to it or, in the opposite tract, through the interventricular defect. The relative strength of each of these pathways will determine the direction and intensity of the blood flow..$^{2-20}$

The distortion of cardiac morphology in congenital heart diseases leads to variable hemodynamic consequences that promote myocardial adaptation and may eventually induce ventricular dysfunction. ${ }^{20}$ In 1960, Somerville, et al. ${ }^{21}$ have observed hemostatic changes in 50 patients with congenital heart disease (40 cyanotic and 10 noncyanogenic), including TOF, tricuspid atresia, pulmonary stenosis, bypass atrial septum, and transposition of the great arteries. Disorders that they identified were hypofibrinogenemia, thrombocytopenia, and the reduction of thromboplastin synthesis. This last change is proportional to the level of polycythemia in patients with heart disease of the cyanogenic type. These disorders are related to an increased bleeding propensity to trauma and/ or surgery in these children. The authors suggested that the bleeding disorders observed in patients with polycythemia could occur as an effect of chronic hypoxemia.

TOF is a multifaceted syndrome, which is underreported and has a high prevalence in pediatrics. According to research carried out in the literature, some cases of TOF concordance have been found to be associated with twinning in the world, though no cases have been reported in Latin America. This fact corroborates the relevance of the present case, which is, to the best of our knowledge, the first case of congenital heart defect concordance for TOF in monozygotic twins in Brazil. Understanding the dimensions and implications of this disease is of great clinical relevance, as pediatric interventions will reflect the adult life of these patients.

\section{Author contributions}

Acquisition of data: Liborio-Neto AO. Writing of the manuscript: Liborio-Neto AO. Critical revision of the manuscript for intellectual content: Liborio-Neto AO.

\section{Potential Conflict of Interest}

No potential conflict of interest relevant to this article was reported.

\section{Sources of Funding}

There were no external funding sources for this study.

\section{Study Association}

This study is not associated with any thesis or dissertation work.

\section{Ethics approval and consent to participate}

This article does not contain any studies with human participants or animals performed by any of the authors. 


\section{References}

1. Gonzalez J, Cadavid A, Aguilera D, Cazzaniga M. Update article for continuos education Tetralogy of Fallot. Rev Colomb Cardiol. 2008; 15(3): 139-47.

2. Barreira MC. Tetralogia de Fallot - Um Desafio Multidisciplinar.2017. Tese. Lisboa: Universidade de Lisboa; 2017.

3. Morgenthau A, Frishman WH. Genetic Origins of Tetralogy of Fallot. Cardiol Rev. 2018;26(2):86-92. doi:10.1097/CRD.0000000000000170

4. Pinto Júnior VC, Magalhães PBK. Cavalcante RC, Carvalho Junior W, Lima JRC,Freitas SM. Epidemiology of congenital heart disease in Brazil. Rev Bras Cir Cardiovasc. 2015 Apr; 30(2):219-24. https://doi. org/10.5935/1678-9741.20150018

5. Carvalho AMF, Pinheiro DTC, Monte JEM,, Carvalho AF,, Carvalho CF, Paes Júnior JN. Tetralogy of Fallot and hypertrophic cardiomyopathy: a rare association. Arq Bras Cardiol. 2003 Feb; 80(2):217-9. https://doi. org/10.1590/S0066-782X2003000200010.

6. Alva C, Gomez C, Gomez F, Jimenes Arteaga S, Yanez L, Ochoa L, et al. Concordance of congenital heart defects in two pairs of monozygotic twins: Pulmonary stenosis and tetralogy of Fallot. Arch Cardiol Mexico. 2010;80(1):29-32

7. Govindan BG. A Case Report of Twin to Twin Transfusion with Tetralogy of Fallot in Both Twins. University Journal of Medicine and Medical Sciences. 2016 ; 2 (7) ISSN:2455-2852

8. Haar BG. Een monozygote tweeling met concordantie voor de tetralogie van Fallot, gespleten verhemelte, vesico-ureterale reflux en preauriculaire fistels [Monozygote twins with concordance for Fallot's tetralogy, cleft palate, vesico-ureteral reflux and pre-auricular fistulas]. Maandschr Kindergeneeskd. 1970;38(9):251-63.

9. Adams HD. Fallot's Tetralogy In Twins. Cardiovasc Dis. 1974;1(2):85-6.

10. Nora JJ, Gilliland JC, Sommerville RJ, McNamara DG. Congenital heart disease in twins. N Engl J Med. 1967;277(11):568-71. doi:10.1056/ NEJM196709142771104

11. Cassidy SC, Allen HD. Tetralogy of Fallot in triplet siblings. The American Journal of Cardiology. 1991 Jun;67(16):1442-4. doi: 10.1016/00029149(91)90481-y.
12. Lu JH, Chung MY, Hwang B, Chien HP. Monozygotic twins with chromosome 22q11 microdeletion and discordant phenotypes in cardiovascular patterning. Pediatr Cardiol. 2001;22(3):260-3. doi:10.1007/ s002460010219

13. Laugel V, Livolsi A, Viville B, Langer B, Messer J, Fischbach M. Tétralogie de Fallot chez un couple de jumeaux monozygotes [Tetralogy of Fallot in monozygotic twins]. Arch Pediatr. 2001;8(4):385-8. doi:10.1016/s0929$693 \times(00) 00215-3$

14. Patel AB, Renge RL. Tetralogy of Fallot in monozygotic twins. Indian Heart J. 2002 Feb; 54(1):83-5.

15. Alva C, Gómez FD, Jiménez-Arteaga S, Yáñez L, Ochoa L. Concordance of congenital heart defects in two pairs of monozygotic twins: pulmonary stenosis and tetralogy of Fallot. Arch Cardiol Méx. 2010 Mar; 80(1):29-32. http://www.scielo.org.mx/scielo.php?script=sci_arttext\&pid=S140599402010000100007\&lng=es.

16. Goodship J, Cross I, Scambler P, Burn J. Monozygotic twins with chromosome 22q11 deletion and discordant phenotype. J Med Genet. 1995;32(9):746-8. doi:10.1136/jmg.32.9.746

17. Yamagishi H, Ishii C, Maeda J, Kojima Y, Matuoka R, Kimura M, et al Phenotypic discordance in monozygotic twins with 22q11.2 deletion. Am J Med Genet. 1998;78(4):319-21.

18. Kádár K. Conotruncalis szívfejlodési rendellenességekben igazolt 22q11 microdeletio [22q11 deletion in conotruncal anomalies]. Orv Hetil. 2005;146(8):363-6.

19. Barrial Moreno J, De León Ojeda NE, Selman-Housein Sosa E, Consuegra Chuairey M T, Bermúdez Gutiérrez G. Presentación de caso. Tetralogía de Fallot y Artrogriposis. Rev Cubana Pediatr. 2009; 81(3) 0-0 Open Access

20. Farah MCK, Castro CRP, Moreira VM, Riso AA, Lopes AAB, Aiello VD O miocárdio na tetralogia de Fallot: estudo histológico e morfométrico. Arq. Bras. Cardiol. 2009 Mar; 92( 3 ): 169-77. http://dx.doi.org/10.1590/ S0066-782X2009000300002

21. Sena TS, Pinheiro Filho SR, Lyra IM, Distúrbios da hemostasia em crianças portadoras de cardiopatias congênitas. Rev Bras Hematol Hemoter. 2010;32(2):149-54. doi: 10.1590/S1516-84842010005 